\title{
ELEMENTOS PARA UNA ECONOMÍA POLITICA DEL REPUBLICANISMO: UN ANÁLISIS CRÍTICO DE LA RENTA BÁSICA DE ALASKA*
}

\author{
TOWARDS A POLITICAL ECONOMY OF REPUBLICANISM: \\ A CRITICAL ASSESSMENT OF ALASKA'S BASIC INCOMESCHEME
}

David Casassas y Jurgen De Wispelaere

Recibido: mayo de 2011.

Universidad de Barcelona y Université de Montréal

\begin{abstract}
Palabras clave: renta básica, republicanismo, libertarianismo, independencia socioeconómica, concentraciones de poder económico, control democrático

Keywords: basic income, republicanism, libertarianism, socio-economic independence, concentrations of economic power, democratic control
\end{abstract}

Resumen: En este artículo presentamos las ideas básicas que subyacen a la teoría política republicana y establecemos una línea de demarcación entre la perspectiva republicana y el libertarianismo de izquierdas, el cual tiene en la renta básica de Alaska su plasmación institucional más natural e inmediata. A partir de ahí, abordamos tres conjuntos de problemas que presenta el modelo de Alaska: la falta de una base económica sustancial, la falta de frenos a la acumulación de poder económico privado y la falta de mecanismos de control democrático sobre los procesos de extracción, imposición tributaria y distribución de los recursos naturales. Así, para que el republicanismo pueda hacerlo suyo, el modelo de Alaska debe ser sometido a importantes enmiendas y modificaciones que tienen que ver tanto con su naturaleza intrínseca como con el contexto institucional en el que opera. De este modo, concluimos sosteniendo que, aun cuando el modelo de Alaska puede ser compatible con la perspectiva republicana en un sentido débil, los republicanos deben proceder con cautela a la hora de defender el modelo en un sentido fuerte.

${ }^{*}$ ) Este texto ha sido elaborado en el marco de un proyecto de investigación financiado por el European Research Council bajo el Séptimo Programa Marco de la Unión Europea (FP7/2007-2013 / ERC / acuerdo n² 249438 - TRAMOD). Una primera versión aparecerá publicada en un libro dedicado enteramente al estudio del modelo de renta básica de Alaska (Widerquist y Howard, 2012a). Queremos agradecer los pormenorizados comentarios que hicieron del borrador de este artículo Simon Birnbaum, Michael Howard, Blain Neufeld, Cristian Pérez, Philip Pettit y Karl Widerquist. 


\begin{abstract}
In this article we present the basic ideas of republican political theory and demarcate the republican perspective from leftlibertarianism, which sees Alaska's basic income model as its more natural and immediate institutional realization. We then address three sets of problems in the Alaska model: the lack of a substantial economic floor, the lack of limits on great accumulations of private economic power, and the lack of mechanisms of democratic control over the extraction, taxation and distribution of natural resources. For republicans to endorse the Alaska model, it will have to be modified extensively. We conclude that, while the Alaska model can be made compatible with the republican perspective in a weak sense, republicans should be cautious about defending the model in a strong sense.
\end{abstract}

\title{
Introducción
}

Desde 1982, cada ciudadano del estado de Alaska recibe una participación igual de las reservas de petróleo del estado, que se gestionan a través de un fondo permanente denominado «Alaska Permanent Fund» (APF), en la forma de un dividendo o subsidio anual de alrededor de 1.000 dólares (el Ilamado «Permanent Fund Dividend», PFD) conferido a cada ciudadano o residente acreditado mayor o menor de edad ${ }^{1}$. El PFD es el único ejemplo existente en todo el mundo de política económica a gran escala que combine la imposición tributaria sobre un recurso natural no renovable con la distribución individual e incondicional de (parte de) la renta acumulada en el fondo soberano constituido a partir de los recursos recaudados.

El PFD ha demostrado ser un programa altamente exitoso que ha gozado de un amplio apoyo por parte de ciudadanos de todo tipo de procedencias o extracciones demográficas, socioeconómicas y políticas. Tal como Scott Goldsmith asegura, "plantear hoy en Alaska cualquier medida política que pueda tener un impacto adverso, en la actualidad o en el futuro, en la cuantía del PFD equivale al suicidio político» (Goldsmith, 2005: 558). Asimismo, los defensores del modelo de renta básica de Alaska (en adelante, modelo de Alaska) sostienen que el PFD constituye una política altamente igualitarista ${ }^{2}$, pues confiere a todos los ciudadanos y ciudadanas una participación igual de un recurso natural que se posee en común, lo que, además, inmuniza tal esquema de algunos de los intrincados problemas normativos a los que supuestamente deben hacer frente los programas redistributivos basados en el gravamen de la renta personal. Por todo ello, y tal como ve- 
remos más adelante con detalle, el modelo de Alaska constituye un mecanismo distributivo que se ajusta perfectamente a los planteamientos de los defensores de las teorías de la justicia de carácter libertariano de izquierdas.

En este artículo evaluamos las ventajas e inconvenientes del modelo de Alaska desde la perspectiva del republicanismo contemporáneo, una aproximación que, en el mundo anglosajón, se ha asociado, fundamentalmente, al trabajo de autores como Quentin Skinner (1992, 1998) y Philip Pettit $(1997,2001)$. In nuce, el republicanismo sostiene que la función de un orden político justo es la de proteger y promover la libertad republicana como no-dominación, que es el tipo de libertad que gozamos cuando vivimos a salvo de (la mera posibilidad de) interferencias arbitrarias por parte de los demás. Para los republicanos, el modelo de Alaska quedaría justificado en la medida en que contribuyera a (o, por lo menos, fuera compatible con) la más amplia libertad republicana para todos los ciudadanos. Nosotros creemos que el PFD adoptado en Alaska suspende este particular examen por razones de lo más importante.

Este artículo procede del siguiente modo. Los epígrafes 1 y 2 presentan las ideas básicas que subyacen a la teoría política republicana y establecen una línea de demarcación entre la perspectiva republicana y la teoría libertariana de izquierdas, una perspectiva, esta última, que, bajo nuestro punto de vista, tiene en el modelo de Alaska su plasmación institucional más natural e inmediata. Una vez establecido un marco de análi- sis para evaluar el modelo de Alaska desde una perspectiva republicana, los tres epígrafes siguientes -3 , 4 y 5 - abordan, cada uno de ellos, un particular conjunto de problemas. Cada uno de estos epígrafes sostiene que, para que el republicanismo pueda hacerlo suyo, el modelo de Alaska debe ser sometido a importantes enmiendas y modificaciones que tienen que ver tanto con su naturaleza intrínseca como con el contexto institucional en el que opera. De este modo, en el epígrafe 6 concluimos sosteniendo que, aun cuando el modelo de Alaska puede ser compatible con la perspectiva republicana en un sentido débil, los republicanos deben proceder con cautela a la hora de defender el modelo en un sentido fuerte.

\section{l. El modelo de Alaska y la libertad}

Lo primero que conviene hacer en punto a evaluar el atractivo político-institucional del modelo de Alaska es preguntarnos, antes que nada, qué puede justificar normativamente (si algo puede hacerlo) el hecho de que adoptemos el modelo en cuestión. Un argumento que nos ofrecería buenas razones para instaurar un esquema de política económica y social como el PFD es el que pasaría por afirmar que éste contribuiría, a través de varios e importantes mecanismos, a ensanchar la libertad individual. Pero el de libertad es un concepto altamente complejo y controvertido, y en el ámbito de la filosofía política existe un importante desacuerdo con respecto a qué elementos hacen que un esquema 
de política pública promueva verdaderamente la libertad de los individuos (Carter, Kramer y Steiner, 2008). Por ello, nuestro objetivo en estos dos primeros epígrafes es el de presentar brevemente los valores centrales de la concepción republicana de la libertad como no-dominación, que anima nuestro análisis crítico del modelo de Alaska, y, también, el de comparar el proyecto de justificación republicano con el propio del libertarianismo de izquierdas ${ }^{3}$.

Empecemos con el libertarianismo de izquierdas, una teoría de la libertad y de la justicia que echa sus raíces en dos valores fundamentales. En primer lugar, la idea de auto-propiedad, que establece, en esencia, que los individuos son propietarios de si mismos, de su cuerpo y de su trabajo, y que tienen un robusto derecho moral a no ser interferidos en aquellas opciones que puedan realizar con respecto a qué hacer consigo mismos, con su cuerpo y con su trabajo: en efecto, hemos de ser libres de ser o hacer lo que nos venga en gana, siempre y cuando no interfiramos en los (igualmente fundamentales) derechos de auto-propiedad de los demás individuos. Por supuesto, para que podamos hacer algo en el mundo de forma efectiva, meros derechos sobre nuestros cuerpos y sobre nuestro trabajo no bastan: de forma inevitable, tenemos que hacer uso de ciertos elementos materiales pertenecientes al mundo exterior. Pues bien, en este punto entra en juego el segundo valor fundamental del libertarianismo. Ocurre, sin embargo, que aquí los libertarianos se dividen en dos grandes familias. Por un lado, los libertarianos tradicionales se acogen a una concep- ción lockeana según la cual el mundo, en su estado inicial "no trabajado», no es propiedad de nadie, por lo que puede ser objeto de apropiación privada -sujeta ésta, eso sí, a la cláusula lockeana según la cual es preciso dejar «tanto y tan bueno a los demás» ${ }^{4}$-. Por el otro lado, los libertarianos de izquierdas creen que el mundo es poseído en común y que, por consiguiente, cualquier uso privado de un recurso del mundo exige el pago de un «canon» o «cuota de utilización» que, a continuación, debe ser distribuida equitativamente entre todos los miembros de la comunidad. Como puede deducirse, aquello que permite a los libertarianos de izquierdas presentarse como igualitaristas es el paso fundamental que realizan de la idea de que el mundo «no trabajado» no tiene propietario a la idea según la cual éste es propiedad común de todos (Cohen, 1995; Otsuka, 2003)5.

Resulta fácil entender por qué el modelo de Alaska puede ser visto como el esquema distributivo libertariano de izquierdas por antonomasia: cada vez que se descubre un recurso que es propiedad de todos -en este caso, el petróleo de los yacimientos de la costa septentrional de Alaska, pero muchos son los bienes y recursos a los que se podría hacer mención en este punto-, está permitido -y quizás obligado- que se introduzca un impuesto sustancial sobre el uso del recurso y que se destine la recaudación resultante a la creación de un fondo público que pueda ser repartido entre todos a través de subsidios de igual cuantía. Tal esquema se adecua a la perfección a la perspectiva libertariana de izquierdas, que aspira a lograr altos 
niveles de igualdad sin por ello violar el principio de auto-propiedad. En efecto, los libertarianos de izquierdas creen que dicha estrategia, consistente en fiar la justicia distributiva a la imposición tributaria de un recurso natural $-y$ no del trabajo-, presenta una ventaja decisiva: permite lograr niveles relevantes de libertad como no-interferencia, por un lado, y de igualdad, por el otro, sin incurrir en formas de explotación como las que se podrían derivar de la imposición sobre la renta personal (Widerquist y Howard, 2012b) ${ }^{6}$. Es por todo ello por lo que decimos que el modelo de Alaska constituye la plasmación institucional de la teoría de la justicia libertariana de izquierdas.

Huelga decir, sin embargo, que dicho mecanismo libertariano de izquierdas consistente en gravar el uso de recursos naturales y, posteriormente, en distribuir esas «cuotas de utilización»-esa recaudación- entre el conjunto de la ciudadanía constituye un esquema de política pública perfectamente compatible con ciertas formas de liberalismo igualitario, de utilitarismo y, por supuesto, también de republicanismo. En otros términos, optar por participar de una estrategia libertariana de izquierdas no obliga a compartir objetivos libertarianos de izquierdas: de lo que se trata, finalmente, es de averiguar hasta qué punto puede interesar, de acuerdo con objetivos (por ejemplo) republicanos, apoyar y ayudar a promover aquellos mecanismos libertarianos de izquierdas consistentes en gravar recursos naturales y en distribuir la recaudación resultante, unos mecanismos que, así, sean compatibles con el doble compromiso del libertarianismo de izquierdas con la auto-propiedad, por un lado, y con la igual distribución del valor de los recursos poseídos en común, por el otro ${ }^{7}$. El hecho de que tradiciones filosóficas distintas compartan el interés en un diseño institucional determinado no es óbice para que ambas tradiciones mantengan sus propios objetivos normativos y evalúen el grado de pertinencia del diseño institucional en cuestión de acuerdo con tales objetivos normativos propios.

Consideremos ahora una aproximación alternativa, pero igualmente comprometida con la centralidad del valor de la libertad, a la cuestión de la justificación normativa del modelo de Alaska: la basada en la noción republicana de libertad como no-dominación (Pettit, 1997, 2001). El republicanismo es una teoría de la libertad que hace de la no-dominación la pieza fundamental de cualquier orden social justo. Dicho de forma resumida, la libertad republicana es aquella que gozamos cuando podemos poner en práctica nuestros planes de vida propios sin tener que sufrir interferencias arbitrarias por parte de otros agentes. Un individuo es objeto de interferencias arbitrarias cuando otro individuo o grupo de individuos está capacitado para interferir en sus planes o elecciones sin tomar en consideración los intereses o proyectos que pueda albergar. De acuerdo con el republicanismo, no es la interferencia per se aquello que restringe la libertad de una persona, sino la arbitrariedad de la interferencia. En efecto, una interferencia -por ejemplo, por parte de las instituciones políticas- que contemple y respete los intereses y proyectos de una persona no 
puede considerarse lesiva de la libertad individual en ningún sentido relevante del término. Al decir de Pettit (1997: 55), «un acto es perpetrado de modo arbitrario, podríamos decir, si sólo está sujeto al arbitrium, a la decisión o al juicio, del agente; si el agente está en una posición en la que puede o no elegirlo, según le plazca. Cuando decimos que un acto de interferencia ha sido perpetrado de un modo arbitrario, la implicación es que, como cualquier otro acto arbitrario, ha sido elegido, o no, según le plazca al agente. Y en particular, puesto que estamos hablando de interferencia en la vida de otros, implica que el acto es elegido, o no, sin atender a los intereses 0 a las opiniones de los afectados. La elección no está obligada a atender a los intereses de los demás, según los juzgan ellos mismos» ${ }^{8}$.

Otro aspecto crucial de la noción republicana de libertad radica en el hecho de que la mera posibilidad de la interferencia arbitraria es suficiente para que la persona deje de ser libre. Cuando la posibilidad de la intervención es suficiente para impedir que un agente planee su vida de acuerdo con sus deseos y aspiraciones, éste deja automáticamente de ser independiente o de autogobernarse, y pasa a gobernar su vida de acuerdo con las razones de otros: así, dicha persona vive literalmente bajo control ajeno (Pettit, 1997, 2001). En cualquier caso, es todo este énfasis en la cuestión de las "razones», así como el interés puesto en la posibilidad de introducir políticamente las condiciones sociales e institucionales que permiten que los individuos efectivamente vivamos atendiendo a nuestras propias razones y no a las de otros, aquello que aleja a los republicanos, conceptual y normativamente, de la obsesiva preocupación de los libertarianos, de derechas o de izquierdas, por la libertad entendida como mera no-interferencia. En efecto, así como los libertarianos ven en cualquier forma de intervención del Estado una fuente inevitable de interferencias arbitrarias -con la excepción de aquella acción estatal que se dirige pura y exclusivamente al reparto de las citadas «cuotas de utilización» de los recursos comunes, pues en este caso el Estado se limita a corregir violaciones previas de los derechos de propiedad-, los republicanos aspiran a que las instituciones políticas intervengan no arbitrariamente en la vida social, precisamente para construir aquellos escenarios sociales que permitan la extensión de los mayores grados posibles de libertad como no-dominación entre el mayor número de personas posible; que permitan, en suma, que el mayor número de personas posible viva de acuerdo con sus propias razones y no con las de otros ${ }^{9}$.

Todos estos postulados descansan en una descripción del mundo u ontología social, la republicana, según la cual la vida social se halla atravesada por todo tipo de vínculos de dependencia. Según el republicanismo, se dan relaciones de dependencia siempre que los individuos, como consecuencia de un acceso disímil a la propiedad o control de los recursos materiales, ocupan posiciones sociales desiguales, lo que permite que unos se encuentren habilitados para interferir arbitrariamente en la vida de otros. Cierto es que el republicanismo, que constituye una teoría de la libertad 
de carácter irreductiblemente social (Pettit, 1993), asume que la realización de los planes de vida de los individuos requiere la presencia de los demás en todas las esferas en las que nuestras vidas se desarrollan, esto es, requiere la coordinación de nuestra acción con la de los demás: al fin y al cabo, el valor de la vida que nuestra libertad ha de hacer posible se halla íntimamente relacionado con el modo en que los demás actúan e interactúan con nosotros. Ahora bien, el republicanismo no deja ni un ápice de duda con respecto a la necesidad de que las instituciones políticas intervengan, siempre de modo no arbitrario, para garantizar -0 , por lo menos, favorecer-que esa interacción social se dé en condiciones de ausencia de dominación o, lo que es lo mismo, se desarrolle de acuerdo con los intereses y razones de todos los agentes, sin exclusiones de ningún tipo. Efectivamente, aquello que el republicanismo reivindica es una protección institucional robusta frente al poder o capacidad de algunos individuos o grupos de individuos de interferir en nuestras vidas sin la debida consideración de nuestros intereses y de nuestras razones para optar por un curso de acción verdaderamente deseado, un curso de acción que, quizás, se torne por ello dificultoso, costoso o directamente imposible. En suma, sólo es ciudadana en un sentido pleno del término aquella persona que es libre, aquella persona que es considerada un miembro de la comunidad política igual a los demás y que, por ello, se ve tan protegida como los demás frente a la mera posibilidad de interferencias arbitrarias. Finalmente, nótese que, por todo ello, el republicanismo no se halla fundamentalmente comprometido con la «libertad de elegir»-option-freedompara poder ser o hacer tanto como podamos querer ser o hacer, sino con la bien distinta «libertad social»-0 agencyfreedom- de vivir la propia vida sin necesitar requerir, a cada paso, el permiso de otros individuos o grupos, sean éstos agentes privados o el Estado y sus dependencias burocráticas (Domènech y Raventós, 2007; Pettit, 2003) ${ }^{10}$.

Desde sus orígenes, la tradición republicana ha hecho hincapié en la importancia de los recursos materiales para la garantía de la independencia socioeconómica de los individuos, la cual constituye una condición necesaria, aunque no suficiente, para que éstos logren y consoliden una posición de invulnerabilidad social que ha de mantenerlos a salvo de cualquier forma de dominación que pueda darse en cualquier esfera de la vida social (Birnbaum y Casassas, 2008; Raventós, 2007). Históricamente, la independencia socioeconómica se hallaba estrechamente vinculada a la propiedad, al hecho de que el sujeto fuese una persona propietaria. Autores republicanos tan distintos como Aristóteles y Cicerón o Harrington y Jefferson compartían la convicción de que sólo los propietarios, que gozan de un conjunto estable de recursos materiales -sean éstos dinero, tierras, animales o incluso esclavos-, pueden llevar una vida civil verdaderamente libre, pues sólo ellos tienen la existencia material garantizada. Como planteaba el propio Harrington, «el hombre que no puede vivir por su cuenta debe ser un siervo; pero el que vive por su cuenta puede 
ser un hombre libre» (Harrington, 1992: 269). Similares consideraciones conforman el ideal de una «democracia de propietarios» 0 «property-owning democracy», ideal que, en la estela del republicanismo jeffersoniano, en el mundo contemporáneo fue retomado por James Meade: «un hombre con la suficiente propiedad posee una mayor fuerza negociadora y un sentido de la seguridad, de la independencia y de la libertad» (Meade, 1964: 39) ${ }^{11}$. Asimismo, conviene destacar el carácter nítidamente republicano-propietarista de la primera defensa moderna de una renta básica: en 1797, Thomas Paine, en su Agrarian Justice, abogaba por la introducción de una renta básica como mecanismo para restaurar los derechos de propiedad sobre los recursos externos que muchas personas habían perdido como consecuencia del cercamiento de los terrenos comunales: "Al considerar la condición de las personas desposeídas, defiendo no un acto de caridad, sino un derecho [...]: la creación de un fondo nacional a partir del cual se pague a todas las personas llegadas a la edad de veintiún años la suma de quince libras esterlinas como compensación parcial por la pérdida de su herencia natural ocasionada por la introducción del sistema de la propiedad privada de la tierra; y también la suma de diez libras al año, a lo largo de toda la vida, a toda persona que actualmente haya llegado a los cincuenta años y a todos aquellos que en el futuro lleguen a dicha edad. [...] Propongo que tales pagos, como ya he sostenido, sean hechos a todas las personas, sean éstas ricas o pobres» (Paine, 1997: 326-7) ${ }^{12}$.
En resumen, para el republicanismo, el acceso a los recursos materiales -esto es, la garantía efectiva, como un derecho, de una base material que garantice nuestra existencia social y económica- constituye una condición sine qua non para el goce del preciado valor de la libertad como no-dominación. Todo ello parece ofrecer una justificación clara de un sistema que, como el modelo de Alaska, ofrezca a cada ciudadano, en la forma de un subsidio universal e incondicional, una participación igual de los ingresos derivados del gravamen impositivo del uso de un recurso de propiedad común. No obstante, una versión republicana de un dispositivo institucional de este tipo presentaría unas características harto distintas de las del modelo que se deriva de los planteamientos libertarianos de izquierdas. Veamos por qué.

\section{En qué difieren republicanos y libertarianos de izquierdas}

Antes de adentrarnos en la evaluación de las características del modelo de Alaska desde la óptica del republicanismo, conviene que nos detengamos en el análisis de tres aspectos en los que la tradición republicana se aparta de la perspectiva libertariana de izquierdas. Tales diferencias explican por qué, a pesar del interés compartido por republicanos y libertarianos de izquierdas en una noción de libertad de carácter social o agency-based, los primeros no pueden participar del entusiasmo con 
el que los segundos enjuician el modelo de Alaska.

La primera diferencia tiene que ver con las disparidades que presentan las nociones de libertad que republicanos y libertarianos de izquierdas manejan. Pese a que ambas escuelas adoptan una concepción de la libertad centrada en la protección frente a las interferencias en la agencia individual y no en la mera expansión del abanico de opciones -por ello ambas son nociones de libertad del tipo agency-based, y no choice-based-, republicanos y libertarianos de izquierdas presentan profundas divergencias a la hora de definir en qué consiste realmente la libertad (Pettit, 2003). Los libertarianos de izquierdas creen firmemente en la libertad como no-interferencia, y lo hacen a partir de unos planteamientos particularmente restrictivos de acuerdo con los cuales cualquier interferencia en el libre uso, por parte de cada individuo, de su cuerpo y de su trabajo ha de quedar explícitamente prohibida por suponer una violación del principio de auto-propiedad. En cambio, según el republicanismo, lo que está en juego y ha de ser considerado normativa y político-institucionalmente es el grado en que todos los ciudadanos pueden vivir sus vidas protegidos frente a cualquier forma de control ajeno de las mismas, y ello bien a menudo requiere interferencias legítimas, esto es, no arbitrarias, por parte de las instituciones políticas. Una implicación importante de esta distinción para el presente análisis radica en el hecho de que allá donde los libertarianos de izquierdas han de limitarse a formas de política pública que no afecten el derecho de todos a disfrutar íntegramen- te del fruto de su propio trabajo o actividad-por ejemplo, la imposición tributaria del uso de recursos naturales respeta este tipo de limitaciones-, los republicanos pueden adoptar una actitud más relajada con respecto a la posibilidad de gravar un abanico más amplio de bienes o recursos, siempre y cuando la intervención (no arbitraria) de las instituciones públicas resulte en un incremento de la libertad republicana entre el mayor número de personas posible ${ }^{13}$.

En segundo lugar, pese a que varios defensores de una estrategia libertariana de izquierdas de imposición tributaria de los recursos naturales insisten en que el modelo de Alaska ha tenido y tendrá un impacto positivo en la reducción de la pobreza, conviene señalar que, en sentido estricto, el libertarianismo de izquierdas no muestra preocupación normativa alguna por la pobreza. Cualquier uso que hagamos de los recursos externos para combatir la pobreza se encontrará en todo momento limitado o restringido por el principio de auto-propiedad y por el de igualdad en el derecho de propiedad del mundo exterior -estos son, recordemos, los principios que establecen que aquellos que utilizan recursos externos deben pagar un canon o «cuota de utilización» a los demás-. Así, la pobreza importa sólo en la medida en que existe una relación directa y clara entre ser pobre y haber sufrido una violación del derecho a la auto-propiedad o del derecho a la propiedad de una parte igual de los recursos del mundo, que son o han de ser de todos. Más allá de estos dos principios, los libertarianos de izquierdas no se hallan conceptualmente 
equipados para interesarse por la pobre$z^{14}$. Así, gravar el uso de los recursos naturales y evitar a toda costa que se grave el trabajo -en esto consiste el modelo de Alaska- constituye una opción segura para los libertarianos de izquierdas, por la simple razón de que ello garantiza que la libertad como no-interferencia que los libertarianos hacen suya quede fuertemente protegida. Ahora bien, el impacto en la reducción de la pobreza de la política pública que resulta de este planteamiento es, en el mejor de los casos, contingente, y muchos somos los que creemos que una teoría de la justicia distributiva debe otorgar a la suerte de los pobres o desposeídos un lugar más destacado. En cambio, el énfasis del republicanismo en la independencia material como condición necesaria de la libertad social mantiene una relación más estrecha con el objetivo de la erradicación de la pobreza. Según el republicansmo, la pobreza, en todas sus formas -esto es, no sólo en sus formas más extremas-, es directamente incompatible con la libertad republicana como no-dominación, pues la carestía de unos recursos materiales básicos es vista como la causa fundamental del tipo de vínculos de dependencia que se hallan en la base de las muy diversas formas de ilibertad (Pettit, 2006; Raventós, 2007).

En tercer lugar, pese a su abierta sensibilidad igualitarista, el libertarianismo de izquierdas hace suya la ontología social propia del individualismo atomista y, en consecuencia, evita comprometerse con una concepción sustantiva de la sociedad política o de la comunidad que vaya más allá de la idea del asociacionismo voluntario (Otsuka, 2003). Pues bien, no es necesario participar de planteamientos colectivistas para apreciar los límites de una concepción meramente agregativa-atomista de la comunidad política en la que la única función de las instituciones públicas sea la de facilitar la compleja coordinación de la agencia individual (Pettit, 1993, 1997). Este problema se muestra de forma diáfana cuando se considera el marco políticoinstitucional que rodea el PFD de Alaska. Tal como Goldsmith plantea convincentemente, la dotación que reciben todos los ciudadanos de Alaska es percibida más como un rendimiento gozado aisladamente que como una partida de gasto del presupuesto gubernamental, que concierne a todos: «existe entre muchos habitantes de Alaska un fuerte sentimiento de que los recursos petroleros propiedad del Estado les pertenecen a ellos como individuos, no a todos los ciudadanos de forma colectiva» (Goldsmith, 2005: 558). Obviamente, hay una poderosa razón por la que unos planteamientos excesivamente individualistas carecen de sentido en un contexto como el del PFD de Alaska: huelga decir que no hay individuo alguno que pueda tomar por su cuenta su parte del recurso directamente de la naturaleza y decidir unilateralmente cómo utilizarlo. En otras palabras, la propia decisión de extraer un recurso, de permitir su uso, de gravarlo y, a continuación, de asignar los fondos recaudados en la forma de un dividendo individual conferido regularmente constituye una decisión colectiva que necesariamente ha de ser tomada por la comunidad política en su conjunto. Volveremos sobre este punto en 
el epígrafe 5. Lo que interesa destacar ahora es que una concepción de lo político de tipo libertariano de izquierdas, esto es, que establezca que la política es el resultado de una mera asociación voluntaria, puede llevar a exagerar los aspectos individualistas del modelo de Alaska. Pues bien, en este punto el republicanismo también ofrece una perspectiva harto distinta de la del libertarianismo. En efecto, la libertad republicana tiene que ver, inherentemente, con la presencia de ciudadanos libres que deciden conjuntamente la constitución de un orden político estable en el cual la libertad republicana de cada ciudadano, que se concreta en formas muy diversas de llevar a la práctica los también muy diversos planes de vida individuales, se encuentra fuertemente protegida por parte de unas mismas instituciones colectivas. Cuando los republicanos hacen hincapié en el valor de la libertad individual, lo hacen siempre sobre la base de un denso tejido de interconexiones sociales y desde la convicción de que la libertad individual es al mismo tiempo libertad social o colectiva, esto es, de que la libertad se sitúa socialmente en términos de igualdad con respecto a los demás: no hay libertad sin reciprocidad en esa misma libertad. En definitiva, el republicanismo es, en esencia, una teoría de la libertad inquebrantablemente unida a una teoría de la política ${ }^{15}$.

Vistos estos tres conjuntos de cuestiones, podemos adentrarnos ya en el examen republicano del modelo de Alaska y de sus potencialidades como herramienta para la transformación social de interés para otras áreas geográficas del planeta.

\section{3. ¿Una base económica?}

Es de suponer que, por lo menos de entrada, los republicanos se muestren de acuerdo con el modelo de Alaska, pues éste aspira, fundamentalmente, a conferir a cada ciudadano una base o suelo económico, una suma de renta regular concebida como el equivalente a una igual participación de los recursos naturales de propiedad común (Goldsmith, 2012) ${ }^{16}$. En efecto, parece que un esquema de este tipo se adecua perfectamente a la pretensión del republicanismo de otorgar a todos los miembros de pleno derecho de la sociedad un nivel básico de recursos materiales que garantice que todos podrán desarrollar sus vidas en condiciones de ausencia de interferencias arbitrarias por parte de instancias ajenas. Esto resulta especialmente importante en situaciones de pobreza extrema, en las que la privación lleva de la mano la dependencia con respecto a los demás para sobrevivir y satisfacer las necesidades más elementales. Pero la garantía de un suelo material básico es también fundamental en punto a fortalecer la libertad de aquellos que se enfrentan a circunstancias menos extremas: en efecto, todos nos hallamos o podemos hallarnos en la tesitura de tener que adaptar nuestras acciones y decisiones a los deseos e intereses de otros actores situados en posiciones de mayor privilegio en términos sociales y económicos. Un típico ejemplo de ello lo encontramos en las muchas formas a través de las cuales un trabajador asalariado ha de aceptar las interferencias arbitrarias de sus llama-

Revista Internacional de Pensamiento Político - I Época - Vol. 6 - 2011 - [165-192] - ISSN 1885-589X 
dos «empleadores» en el desarrollo de sus vidas productivas o profesionales -y bien a menudo también en los aspectos más íntimos de sus vidas privadas-. Así, la presencia de una base económica, al garantizar una existencia material independiente, permite mejorar la posición negociadora de los ciudadanos en la esfera económica (Birnbaum y Casassas, 2008; Casassas, 2007; Raventós y Casassas, 2004).

Pero ¿qué tipo de base económica puede jugar dicho papel? En este punto conviene tomar en consideración varias cuestiones. En circunstancias ideales, la base económica en cuestión debería ser suficiente para garantizar plenamente la existencia material de una persona, esto es, para satisfacer sus necesidades básicas (Goodhart, 2007; Raventós, 2007). No obstante, conviene señalar que la noción de necesidades básicas es controvertida y presenta múltiples dimensiones, y los republicanos aceptan que la naturaleza exacta de la base económica debe ser adaptada al particular contexto social en el que un ciudadano ha de desarrollar su vida. Además, la relación que media entre la seguridad material y la libertad republicana dista de ser simple o lineal. En efecto, la base económica deber ser concebida como un bien escalar o step good que contribuye a ampliar la libertad republicana de forma discontinua, esto es, a través de mecanismos que entran en funcionamiento a través de secuencias vinculadas de un modo discreto: el efecto directo de un incremento gradual de la base económica en la libertad como nodominación de una persona puede ser escaso o nulo hasta que no se alcance un «punto crítico» en el que un «nivel superior» de libertad republicana se materializa. Si bien la satisfacción de las necesidades básicas constituye un ejemplo de «punto crítico» bastante obvio, pues en él pasa a ser posible (o más probable) que los individuos abandonen o «salgan» de aquellas relaciones sociales que deterioran su libertad, podemos imaginar otros importantes «puntos críticos» o «esquinas» situados por encima o por debajo del nivel de las necesidades básicas que contribuyan también, y de modos harto relevantes, a la ampliación de la libertad republicana. Sea como sea, y de acuerdo con esta interpretación de la base económica, conviene señalar con claridad que dicha base económica no puede ser de un nivel tan bajo que contribuya sólo de un modo trivial a potenciar la libertad como no-dominación de los ciudadanos: la libertad republicana requiere una base económica sustancial.

En el caso de Alaska, los republicanos han de aplaudir y aplauden la idea de un esquema de transferencia de recursos que garantice universal e incondicionalmente un flujo de renta para todos los ciudadanos. No obstante, en el caso concreto del PFD surgen varias dificultades. Si bien no son insignificantes en términos de capacidad de consumo, especialmente cuando se gastan en bienes duraderos y en otro tipo de inversiones para el hogar, 1.200 dólares anuales quedan francamente lejos de lo que podría suponer una contribución significativa a la libertad republicana. Contar con la posibilidad de adquirir al final del año esa lavadora de ropa que tanto hemos echado en falta durante 
tanto tiempo puede ayudar a un hogar en muchos sentidos, pero no conferirá a un trabajador asalariado el tipo de poder de negociación que precisa para hacer frente a las exigencias de su poderoso empleador, ni permitirá a una mujer imponer un reparto del trabajo doméstico y de cuidado más justo y respetuoso con sus deseos y aspiraciones ${ }^{17}$. Cierto es que disponemos de muy poca evidencia concreta acerca de patrones de gasto del PFD de Alaska, pero nos inclinamos a pensar que el diseño del esquema como un bono anual satisfecho precisamente durante el período navideño hace más probable que sea percibido y tratado como un obsequio que como parte de la renta regular del ciudadano ${ }^{18}$. Esto refuerza la idea de que el PFD constituye un beneficioso complemento para el consumo, pero no una parte del tipo de base económica que el republicanismo reivindica. $Y$ aunque optar por un pago mensual de unos 100 dólares podría contrarrestar la peculiar presentación como «bono navideño» del actual PFD, ello tendría pocas consecuencias en ausencia de un incremento significativo de la cantidad total del dividendo. En definitiva, puede que los ciudadanos de Alaska se hallen en una mejor situación en términos de bienestar, pero difícilmente se puede afirmar que el PFD los haga más libres en el sentido republicano de la libertad como no-dominación ${ }^{19}$.

A menudo se plantea que conviene no dejarse cegar por el nivel actual del PFD, pues se podrían encontrar vías fáciles para hacer incrementar esas cifras. Por un lado, se pueden incrementar los ingresos «internamente», sea aumentan- do las tarifas de los permisos de explotación de los yacimientos -en la actualidad, perforar los yacimientos de Alaska resulta realmente barato-, sea dedicando una parte superior de los ingresos obtenidos por el APF al pago de los dividendos individuales -o combinando ambos mecanismos- (Widerquist y Howard, 2012b). Por otro lado, se podría proceder «externamente», tratando de incrementar la base imponible incluyendo en el sistema otros recursos naturales como ciertos minerales, el suelo o todo un nuevo abanico de recursos que normalmente no se consideran y que podría incluir elementos como el espectro de emisión de contenidos audiovisuales (Bollier, 2006) o la propia atmósfera global (Howard, 2012). Sin embargo, en este punto conviene señalar tres importantes dificultades que no pueden escapar a un análisis republicano de las potencialidades y perspectivas del modelo de Alaska. En primer lugar, la aspiración política a ampliar los rendimientos del sistema, sea dicha ampliación de tipo «interno» o «externo», no debe reducirse a un acto de fe ciega en las posibilidades existentes de lograr tales objetivos, en particular vista la enorme magnitud en que el PFD debería aumentar para llegar realmente a constituir una base económica capaz de ampliar de forma efectiva la libertad republicana del conjunto de la ciudadanía: huelga decir que tales incrementos de la cuantía percibida por los ciudadanos requerirían importantes modificaciones en el funcionamiento de mercados y sectores de actividad enteros, por lo que sería de esperar que quienes pretendieran introducirlas se encontraran con la más fe- 
roz de las resistencias por parte de los actores potencialmente perjudicados. En segundo lugar, conviene tener presente también que no siempre resulta conveniente ampliar la base imponible de un sistema como el de Alaska, pues ello implica poner en venta recursos que, por razones ético-políticas de diversa índole -por ejemplo, su alto valor social o su escasez-, se considere necesario mantener desmercantilizados. En tercer lugar, muchos defensores del modelo de Alaska y de la renta básica en general tienden a pensar que, en lo que respecta a la magnitud del subsidio, «menos es nada», razón por la cual se muestran partidarios de un esquema modesto y parcial, incluso no plenamente universal e incondicional, capaz sólo de generar un pago de cuantía realmente escasa. Al margen de cuestiones de estrategia y táctica políticas cuya consideración no tiene sentido en este contexto, lo que conviene aclarar en este punto es que, de acuerdo con la perspectiva republicana, no existen razones de índole normativo para dar apoyo a escenarios de este tipo. En efecto, para los republicanos, tales opciones sólo son normativamente defendibles cuando se cuenta con expectativas razonables con respecto a las posibilidades de que tal renta básica parcial se amplíe hasta alcanzar su versión plenamente desarrollada, pues sólo una renta básica plenamente desarrollada contribuye a fomentar aquello que el republicanismo realmente valora: la libertad como no-dominación ${ }^{20}$

Consideremos, finalmente, una última cuestión. A menudo se habla de la base económica -de la renta básica, en suma- como si ésta, por sí sola, fuera capaz de generar todos los deseables efectos beneficiosos que le podamos atribuir. Esto puede tener sentido cuando analizamos las cosas en términos de poder adquisitivo, pues cualquier incremento de efectivo disponible puede transformarse de un modo relativamente sencillo en mayor capacidad de compra. Pero las cosas son algo más complejas cuando las analizamos desde la perspectiva de la normatividad republicana. Para que una base económica promueva de forma efectiva la libertad republicana, dicha base económica debe formar parte de un conjunto más amplio de políticas sociales que incluya elementos igualmente importantes en punto a garantizar la independencia socioeconómica de los ciudadanos como, por ejemplo, prestaciones en especie como el acceso a una sanidad y a una educación públicas y de calidad, servicios de cuidado a las personas, políticas de empleo, etc. Para utilizar unos términos inspirados en el debate sobre las libertades básicas en Rawls, podemos distinguir entre la «base económica» y el «valor de la base económica» (Daniels, 1989). La «base económica» viene dada meramente por la cuantía de la asignación. En cambio, el «valor de la base económica» depende del contexto político amplio en el que tal asignación se percibe. Así, un PFD introducido en el contexto de un régimen de bienestar de tipo liberal tendrá un impacto distinto en la libertad republicana de los ciudadanos que uno introducido en un contexto abiertamente conservador $u$ otro que se acomode en un contexto de naturaleza socialdemócrata (Esping-Andersen, 1990; Haagh, 
2011). Como puede observarse, tomar en consideración el contexto político nos permite advertir que una asignación de cuantía relativamente (pero no excesivamente) reducida ubicada en el seno de paquetes de medidas orientados a garantizar integralmente niveles relevantes de seguridad socioeconómica puede incrementar la libertad republicana en mayor medida que un marco institucional en el que una asignación de mayor cuantía constituya el único mecanismo para el empoderamiento de los más débiles ${ }^{21}$. En definitiva, los republicanos aciertan cuando desconfían de cualquier forma de «fetichismo de la renta básica»: es falso que cualquier renta básica sirva para el progreso de la libertad republicana como no-dominación. Por ello, una evaluación republicana del APF y del PFD debe incorporar un análisis pormenorizado de aquellas condiciones políticas bajo las cuales los republicanos hallan razones realmente convincentes para defender la adopción de un modelo como el de Alaska.

\section{4. ¿Un techo económico?}

El establecimiento de una «base económica» como garantía de la existencia material de los ciudadanos constituye sólo una parte de la preceptiva políticoinstitucional republicana. La preocupación con respecto a la promoción de la libertad republicana de los agentes, entendida ésta, como ya se ha visto, como ausencia de la mera posibilidad de interferencias arbitrarias, exige también el establecimiento de lo que podríamos llamar un «techo económico». La lógica subyacente a este tipo de mecanismo es, de nuevo, bastante sencilla. De acuerdo con el republicanismo, la falta de libertad tiene que ver también con la presencia de grandes desigualdades de poder económico en los más diversos ámbitos de la vida social. Por mucho que los individuos hayan sido empoderados a partir de un conjunto básico de recursos conferido incondicionalmente, la posibilidad de que emprendan caminos productivos y vitales propios, fundamentados en opciones genuinamente autónomas, se ven cercenadas cuando ciertos grupos de actores pueden controlar a su antojo mercados y economías enteras, definiendo pro domo sua las reglas del juego del conjunto -o de ámbitos decisivos- de la vida social (Birnbaum y Casassas, 2008; Casassas, 2010). En efecto, las grandes acumulaciones de poder económico privado normalmente se concretan en la capacidad, por parte de unos pocos, de constituir monopolios y oligopolios; en la introducción de barreras de entrada a los mercados; en la fijación predatoria de precios; en el control privado de recursos estratégicos; en la restricción de la democracia, la autonomía y la autorrealización en el centro de trabajo; y un largo etcétera. Así, las grandes desigualdades que observamos en nuestras sociedades de tipo winner-takes-all (Frank y Cook, 1995) se hallan estrechamente vinculadas a grandes procesos de concentración del poder económico que, a su vez, conllevan grandes diferencias en términos de capacidad de incidencia en la conformación de la naturaleza del espacio social y económico en el que 
nuestras vidas se desarrollan o deberían poder desarrollarse. En este contexto, una base económica como la renta básica, al garantizar la existencia material del conjunto de la ciudadanía -en el caso, claro está, de que tal renta básica sea de una cuantía por lo menos equivalente al umbral de la pobreza-, coadyuva a reequilibrar parcialmente la situación, mejorando la posición de los más vulnerables frente a la posibilidad de interferencias arbitrarias y de todo tipo de relaciones de dominación. No obstante, una medida de este tipo resulta a todas luces insuficiente en una sociedad en la que ciertos actores y grupos de actores logran hacerse con niveles desproporcionados de poder económico que los habilitan para determinar unilateral y arbitrariamente mercados y economías enteras y, en definitiva, los modos de vida del conjunto de la población. Por ello, la libertad republicana exige mecanismos adicionales que, sin socavar el papel que juegan los incentivos en el seno de economías complejas y diversas, permitan controlar ciertas prácticas de los agentes económicos más poderosos.

Existen dos tipos de «techos» capaces de contener el potencial liberticida de las grandes desigualdades económicas. El primero lo constituyen todas aquellas medidas de carácter «regulador» orientadas a evitar que determinadas prácticas asociadas a la presencia del dinero y del mercado penetren en esferas de la vida social que se estime que han de quedar libres de toda lógica venal o mercantil. Tales medidas, auténticas formas de «bloqueo del intercambio» (Walter, 1983) ${ }^{22}$, permiten la presencia de desigualdades económicas, pero imponen un techo regulador que restringe al abanico de cursos de acción al alcance de aquellos agentes que han logrado acumular grandes cantidades de riqueza y poder económico, lo que puede tener importantes efectos en términos de reducción de la capacidad de interferencia arbitraria por parte de tales agentes en las vidas de los demás ciudadanos. De hecho, sociedades como la norteamericana poseen una larga historia de regulaciones orientadas a evitar que los actores sociales y económicos más poderosos erosionen la libertad de los ciudadanos menos favorecidos (Sunstein, 1993). Pensemos, sin ir más lejos, en las regulaciones introducidas durante la llamada «era progresista» y, también, durante la Administración Roosevelt, regulaciones que tenían como objetivo el fortalecimiento de las bases económicas de la democracia y que pasaban por restringir institucionalmente el conjunto de oportunidades de los actores más poderosos, potenciales «monarcas económicos»(Beard y Beard, 1939).

El segundo tipo de «techo» consiste en limitar de forma directa el alcance de las desigualdades económicas. Sin tener por ello que mantener compromiso alguno con un principio de estricta igualdad de recursos, los republicanos tienen razones para mostrarse preocupados por la naturaleza y el funcionamiento de una sociedad en la que un «empleador» gane, por ejemplo, 150 veces lo que gana su empleado medio. Este no es el lugar para analizar detenidamente las ventajas e inconvenientes de cada uno de estos tipos de "techo». Además, los republicanos deberían po- 
der optar por aquel de ellos -o por aquella combinación de ellos- que mejor funcione en una sociedad determinada. Sin embargo, parece razonable pensar que, siempre que haya espacio para que opere en una medida razonable la lógica de los incentivos y para la proliferación de proyectos productivos de índole bien diversa, una estrategia rousseauniana consistente en evitar ex-ante la formación de grandes concentraciones de poder económico y la consiguiente consolidación de grandes desigualdades de ingresos y de riqueza puede ser preferible, normativa y político-institucionalmente, a cualquier intento de reducir expost las consecuencias negativas de tales desigualdades en términos de deterioro de las libertades individuales y colectivas (Rousseau, 2010). En cualquier caso, nada en nuestro examen del modelo de Alaska anima a pensar que debamos comprometernos necesariamente con un camino u otro. Lo único que interesa subrayar en este punto es que, a nuestro modo de ver, la libertad republicana exige no sólo una base económica, sino también un sólido techo económico.

Sea como sea, ¿qué efectos tiene la toma en consideración del requisito republicano de un techo económico en nuestra evaluación del modelo de Alaska? Una respuesta posible a este interrogante podría consistir en afirmar que esta cuestión es irrelevante, porque el PFD está relacionado sólo con el objetivo de la base económica, de modo que su naturaleza y funcionamiento es independiente del hecho de que se introduzca o no un techo económico de un tipo o de otro. En efecto, los defensores del mo- delo de Alaska podrían sostener que éste se mantiene deliberadamente agnóstico con respecto a la necesidad o no de un techo económico, y que si los republicanos consideran oportuno introducirlo, deberán fundamentar dicha opción en planteamientos que queden aparte: bien mirado, nada del modelo de Alaska les impide hacerlo. Esta respuesta puede parecer a primera vista plausible, pero si analizamos con esmero, desde la perspectiva del republicanismo, el vínculo que opera entre la base y el techo económicos, nos percataremos de la necesidad de plantear dos importantes problemas al respecto.

En primer lugar, consideremos una cuestión a la que ya se hizo mención en el epígrafe anterior: el valor de la base económica depende del contexto políticoinstitucional en el que el PFD se implante. Pues bien, la presencia o no de un techo económico, así como la naturaleza del mismo, constituye un elemento decisivo en la conformación de dicho contexto. En efecto, el interés normativo y político-práctico que los republicanos otorgarán a una base económica instituida alrededor de una asignación como el PFD dependerá en gran medida del efecto que éste tenga en la correlación de fuerzas -en el poder de negociaciónque medie entre los distintos (grupos o clases de) ciudadanos. Y en este punto la cuestión del techo juega un papel crucial, pues una sociedad en la que todos los ciudadanos tengan la existencia material garantizada pero en la que los (grupos de) actores económicos más poderosos logren retener su capacidad de controlar social y económicamente los modos de vida de los demás distará 
de constituir un escenario elementalmente libre en términos republicanos. En tales situaciones, la libertad republicana otorgada por la base económica será, en el mejor de los casos, imperfecta, con lo que los republicanos deberán explorar otras opciones más eficaces que puedan conferir niveles más altos de libertad. En definitiva, si tomamos en consideración la inversión de tiempo, esfuerzo, capital político y, por supuesto, recursos económicos que supone la institución de un suelo material básico, nos percataremos de la necesidad de que tal inversión surta los mayores y más fructuosos efectos posibles: ¿podría ser más conveniente que los recursos necesarios para introducir una renta básica del tipo del PFD de Alaska se emplearan en otro tipo de políticas en caso de que no contemos con la seguridad de que podremos llegar a imponer regulaciones à la Roosevelt y/o restricciones antiacumulatorias à la Rousseau? En suma, fracasar en el intento de establecer el «techo» puede conllevar un elevado coste de oportunidad, visto lo poco que pueden ofrecer para el progreso de la libertad republicana los recursos necesarios para constituir ese «suelo» desprovisto de «techo» en comparación con lo mucho que (quizás) podrían ofrecer esos mismos recursos en caso de que fueran empleados en otro tipo de políticas (quizás) más eficaces para la lucha contra la dominación. Sin duda, tales consideraciones distan de apuntar a cuestiones triviales que los republicanos puedan obviar tranquilamente: bien al contrario, tienen un efecto directo e inmediato en las razones republicanas para defender o no una propuesta como la renta básica.
En segundo lugar, los defensores del modelo de Alaska, frente a tales consideraciones, podrían sugerir la adopción de una estrategia gradual consistente en introducir primero una base económica sustancial, para proceder después, y sólo después, a complementar dicho suelo construyendo un robusto techo regulador -à la Roosevelt- o igualitarista -à la Rousseau-. Al fin y al cabo -podrían argumentar-, una vez asumido que el PFD es compatible con la presencia de un techo económico, los republicanos siempre tendrán la opción de tratar de promover integralmente su libertad como no-dominación a través de una secuencia doble que pase por añadir a la base económica el techo por el que también abogan. Esta respuesta es plausible siempre que asumamos que la base y el techo son totalmente independientes, esto es, siempre que asumamos que no existen ni efectos que los vinculen ni formas de path dependence de ningún tipo. Y lo cierto es que las cosas difícilmente serán así. De hecho, existen buenas razones para pensar que la naturaleza institucional del modelo de Alaska tiene importantes efectos en las oportunidades políticas de construir un techo económico robusto. Tal como Scott Goldsmith ha mostrado con perspicacia, el PFD se convirtió enseguida en un estipendio vivido como un derecho meramente individual pasivamente recibido y no como algo que la comunidad política o el Estado distribuye en un sentido activo (Goldsmith, 2005, 2012). En efecto, lo que parece que ha ocurrido en Alaska es que el PFD ha alimentado una concepción de la política económica de carácter marcadamente libertariano que 
por un lado establece que es legítimo gravar el uso de los recursos naturales de propiedad común y distribuir individualmente la recaudación entre el conjunto de la ciudadanía, pero que por el otro postula que hay que contemplar con la mayor de las cautelas cualquier forma de redistribución económica directa basada en figuras tributarias de carácter general, así como cualquier intento de regular la economía con arreglo a criterios de justicia (re)distributiva. Se trata de una concepción libertariana de la política pública que, como puede observarse, no sólo favorece que la justificación de la base económica sea independiente de la del techo, sino que, además, conlleva que la defensa de la base entre en contradicción con la del techo. Huelga decir que tales planteamientos están inherentemente reñidos con la perspectiva teórica y política del republicanismo, lo que ofrece una nueva razón para que los republicanos observen el modelo de Alaska con prudente cautela.

Obviamente, conviene no llevar los argumentos demasiado lejos: bien mirado, puede que los republicanos, en un plano de análisis estrictamente prácti$\mathrm{co}$, no tengan motivos para oponerse a la institución de un PFD, incluso en ausencia de un techo económico. Ello es así especialmente en el caso de que las perspectivas de que a corto o medio plazo se puedan introducir otro tipo de medidas de carácter transformador sean poco favorables. Pero que no haya confusión: en la medida en que la falta de un techo económico erosione decisivamente la capacidad de la base económica para promover la libertad republi- cana, las razones que puedan mover a los republicanos a apoyar la introducción del PFD difícilmente serán razones republicanas.

\section{5. ¿Mecanismos de control democrático?}

Una tercera fuente de dificultades que la tradición republicana puede identificar en el modelo de Alaska tiene que ver, no ya con aspectos distributivos en sentido estricto, sino con la cuestión, de alcance más general, de la presencia o no de un marco político abiertamente democrático para la constitución y administración del sistema. Tal como Widerquist y Howard (2012b) exponen, el punto de partida del APF es la idea de un recurso de propiedad colectiva a partir del cual se constituye un fondo de riqueza soberano poseído en común por parte de todos los miembros de la sociedad. Sin embargo, tal como Goldsmith muestra, los orígenes cívico-políticos del PFD han sido altamente cuestionados por sus propios beneficiarios, quienes prefieren verlo como un derecho individual que es preciso resguardar y poner a salvo de la (supuestamente) tornadiza y caprichosa esfera política (Goldsmith, 2005, 2012). Así, las dificultades existentes a la hora de dar cobijo al APF en el seno de un marco político-institucional dinámico y participativo ponen en evidencia la naturaleza abiertamente individualista del (libertariano) modelo de Alaska, y plantean importantes problemas para la adopción del mismo por parte del republicanismo, el cual participa de una concepción de 
la sociedad y de la política como un proyecto de auto-determinación colectiva.

Para entender cabalmente el problema que se nos plantea, conviene tomar en consideración una distinción central en el concepto de propiedad, a saber: la que establece una línea de demarcación entre el beneficio y el control. El propietario legítimo de un recurso puede obtener todos los beneficios del mismo sin por ello tener un control pleno del modo en que dicho recurso es utilizado, del modo en que se expiden los permisos para su explotación, del modo en que es vendido, etc. (Grey, 1980; Fama y Jensen, 1983). Pues bien, cuando los defensores del modelo de Alaska hablan de «propiedad común», restringen la idea de propiedad a la cuestión de la percepción del beneficio derivado del recurso, y desatienden por completo la dimensión del control del recurso. Y lo cierto es que, cuando se plantea la constitución política de una fondo de riqueza soberano como el APF, hay que tomar tres decisiones fundamentales que se hallan estrechamente vinculadas a la dimensión del control: qué recursos se extraen o se permite que manos privadas extraigan; en qué medida se grava el recurso en cuestión; y de qué modo se asigna la recaudación resultante. A nuestro modo de ver, la ciudadanía de Alaska cuenta con escasa -si no nulacapacidad de control democrático sobre estas tres decisiones -quizás tenga sólo la posibilidad de ejercer cierto (limitado) control «virtual» sobre el tercer aspecto, esto es, sobre el modo en que se asigna la recaudación ${ }^{23}$. Del mismo modo que el APF se halla constitucionalmente protegido a través de una es- tricta «regla de prudencia en la inversión» que los órganos de gobierno del APF institucionalizaron en los orígenes del sistema, el PFD se encuentra también fuertemente protegido, en este caso a través de un derecho de veto colectivo en virtud del cual los beneficiarios impiden cualquier cambio en el funcionamiento del modelo que pueda tener algún efecto en la magnitud de sus percepciones actuales o futuras (Goldsmith, 2005, 2012). Desde la perspectiva de la teoría republicana de la democracia, el margen de maniobra del que gozan los ciudadanos, que se limita a los citados mecanismos, resulta restrictivo en demasía. En efecto, una sociedad democrática debería incrementar las posibilidades al alcance de los ciudadanos en punto a determinar colectivamente qué recursos naturales se gravan, qué parte de la recaudación obtenida ha de ser asignada bajo la forma de dividendos individuales, a través de qué procedimientos deben los individuos percibir tales asignaciones - una vez al mes, una vez al año, una vez en la vida bajo la forma de un capital básico, etc. ${ }^{24}$. En definitiva, resulta obvio que una gobernanza democrática de este tipo implica la adopción de una perspectiva políticoinstitucional radicalmente distinta de la que gobierna el actual modelo de Alaska, que ve el PFD como un derecho natural estrictamente privado e individual que ha de quedar desvinculado de la esfera política a toda costa.

Karl Widerquist propone un cambio en el modelo que permitiría incrementar el control de los ciudadanos sobre su participación de los recursos comunes. Convirtiendo el PFD en lo que él deno- 
mina «Cuentas de Capital Ciudadanas» (en inglés, "Citizens Capital Accounts», CCA), se ofrecería a cada ciudadano un mayor control sobre la gestión de su participación y sobre el uso del dividendo resultante. Al decir de Widerquist, se trataría de que cada niño recibiera, en el momento de su nacimiento, unas participaciones de un fondo de propiedad y gestión gubernamental consistente en inversiones diversificadas como acciones, bienes inmuebles, materias primas y bonos estatales. La característica básica de las CCA sería la siguiente. El propietario de la cuenta -es decir, el ciudadano- tendría acceso sólo a los rendimientos de su cuenta, no al principal. Ahora bien, el propietario -el ciudadano- tendría el derecho a retirar los rendimientos disponibles del modo que más le placiera: una vez al año, mensualmente, semanalmente, diariamente, etc. De hecho, también podría optar por no retirarlos y dejar así que se fuesen acumulando hasta cierta fecha futura. En cualquier caso, una cantidad fija de los rendimientos debería ser reinvertida, lo que aseguraría que el principal incrementase cada año. En el momento de la muerte del ciudadano, la totalidad del principal -pero no los rendimientos disponiblessería depositada en un fondo nacional destinado a financiar las cuentas de la siguiente generación, y los rendimientos disponibles en la cuenta del finado pasarían a formar parte de su herencia y serían gravados y transmitidos a los herederos de acuerdo con lo establecido por la ley tributaria (Widerquist, 2012).

La tradición republicana no puede sino aplaudir el incremento del control y de la responsabilidad que supondría un modelo como el de las CCA. Sin embargo, quienes participan de dicha tradición se ven obligados a señalar que las CCA seguirían siendo un modelo insuficiente en términos de control democrático pleno, pues se centraría sólo en la última decisión -la forma en que se reparten los rendimientos- $y$, en cambio, dejaría fuera del ámbito de lo debatible cuestiones tan importantes como qué recursos hay que explotar y en qué grado conviene gravarlos impositivamente. Huelga decir que éstas son decisiones políticas cruciales que afectan profundamente a la naturaleza y al funcionamiento de la comunidad política, por lo que deberían ser objeto de autodeterminación colectiva y de férreo control democrático. Además, la ausencia de una perspectiva genuinamente democrática sobre estas cuestiones es difícil de entender vista la naturaleza de la nueva agenda medioambiental global. En efecto, como se ha dicho ya, una forma sencilla de incrementar la cuantía del PFD sería la explotación de más (tipos de) recursos, pero ello podría entrar en conflicto con otros valores -fundamentalmente medioambientales-, por lo que, en lugar de quedar totalmente aislado de la esfera política, debería ser objeto de un debate público dinámico y sostenido a lo largo del tiempo en el que todas las voces fueran escuchadas ${ }^{25}$.

Una perspectiva que deja el APF fuera del ámbito de lo político, como ocurre actualmente, o que se limita a ofrecer una cierta mejora en el control de las participaciones individuales pero que coarta el poder de decisión de la gente con respecto a las grandes cuestiones relativas a la extracción y al gravamen 
de los recursos, como ocurre en el modelo propuesto por Widerquist, limita extraordinariamente la capacidad de la comunidad política de determinar colectivamente qué hacer con los recursos que posee en régimen de propiedad común. De acuerdo con el republicanismo, este control democrático es esencial, pues el ámbito político es el espacio en el que los individuos se constituyen como ciudadanos comprometiéndose con el proyecto colectivo de instituir aquellos medios institucionales que puedan proteger la libertad como no-dominación de todos y cada uno de ellos (Pettit, 1997). En una misma dirección, Erik Olin Wright (2006: 6) ha sugerido que la renta básica puede «fortalecer el poder de la sociedad civil en punto a definir las prioridades en el uso del excedente social y en la organización de la actividad económica». La tradición republicana propone un amplio abanico de mecanismos institucionales para la mejora del control democrático, sea en la esfera electoral, es decir, a través de formas de representación política tan perfeccionadas como sea posible, sea en la esfera de la "contestación», esto es, a través de una gran variedad de procedimientos no electorales como los movimientos sociales y las asambleas y tribunales para la expresión pública y canalización institucional de las razones e intereses del conjunto de la ciudadanía ${ }^{26}$. Las soluciones prácticas son abundantes, pero en ausencia de un compromiso claro con el control democrático de todos los aspectos del modelo de Alaska -extracción, gravamen impositivo y distribución-, los republicanos no pueden sino mostrarse escépticos ante la viabilidad del modelo dentro y fuera de Alaska.

\section{Conclusiones}

En este artículo, hemos querido analizar críticamente las ventajas e inconvenientes del modelo de Alaska desde la perspectiva republicana, que se compromete de forma fundamental con la garantía de la libertad como no-dominación de los ciudadanos. Pese a que de entrada parece altamente prometedor, el modelo de Alaska presenta por lo menos tres conjuntos de problemas que deberían preocupar a los defensores republicanos de la renta básica: la falta de una base económica sustancial, la falta de un sólido techo económico y la falta de mecanismos de control democrático sobre los procesos de extracción, imposición tributaria y distribución de los recursos naturales. Creemos que estas tres cuestiones obligan a los republicanos a andarse con cautela a la hora de enjuiciar el modelo de renta básica actualmente existente en Alaska y, también, a la hora de plantear la posibilidad de introducirlo en otras partes del mundo.

Tal como hemos observado a lo largo del artículo, una cosa es adoptar una política que mejore el bienestar de la gente -lo cual constituye, sin lugar a dudas, un objetivo loable- y otra, bien distinta, introducir una política que amplíe significativamente su libertad republicana. $Y$ cuando uno se compromete con el más exigente objetivo de promover la libertad republicana de la gente, debe estar constantemente en busca de polí-

Revista Internacional de Pensamiento Político - I Época - Vol. 6 - 2011 - [165-192] - ISSN 1885-589X 
ticas alternativas que favorezca el mayor nivel posible de libertad republicana para el mayor número de personas. En ausencia de signos claros con respecto a las posibilidades de que el modelo de Alaska amplíe de modo efectivo y genuino la libertad como no-dominación del conjunto de la ciudadanía, el apoyo que los republicanos puedan dar a dicho modelo debe ser provisional y contingente. Ello es así, sobre todo, ante la evidencia de que la institución del modelo de Alaska requiere una inversión considerable de tiempo, esfuerzo, capital político y recursos económicos, lo que implica la presencia de importantes costes de oportunidad. Y tales costes de oportunidad pueden convertirse en prohibitivos cuando la base económica obtenida a través del modelo de Alaska no logra garantizar los niveles de independencia socioeconómica que son nece- sarios para el robustecimiento de la libertad republicana. Por si ello fuera poco, las cosas se complican todavía más cuando se hace patente que el modelo presenta potenciales efectos negativos derivados del hecho de que constituye un esquema que lleva de la mano una cultura demasiado apolítica en la que brilla por su ausencia la cuestión del control democrático y colectivo del uso de los recursos comunes de los que emanan los pagos que los individuos reciben. Así las cosas, cuando se toman en consideración las razones específicamente republicanas que nos podrían llevar a adoptar un modelo como el de Alaska, se pone de manifiesto que la perspectiva republicana presenta condiciones más restrictivas que las que establecen muchos de los que incansablemente defienden la vía de Alaska hacia una sociedad más libre e igualitaria.

\section{Bibliografía}

Ackerman B. y Alstott, A. (1999): The Stakeholder Society, New Haven: Yale University Press.

Arneson, R. (1995): «Against 'Complex' Equality», en D. Miller y M. Walzer (eds.), Pluralism, Justice, and Equality, Oxford: Oxford University Press.

Arneson, R. (2010): «Self-Ownership and World Ownership: Against LeftLibertarianism», Social Philosophy \& Policy, 27(1), pp. 168-194.

Barry, B. (1995): «Spherical Justice and Global Injustice», en D. Miller y M. Walzer (eds.), Pluralism, Justice, and Equality, Oxford: Oxford University Press.
Barry, B. (2005): Why Social Justice Matters, Cambridge: Polity Press.

Beard, C.A. y Beard, M.R. (1939): America in Midpassage, Nueva York: Macmillan.

Birnbaum, S. y Casassas, D. (2008): «Social Republicanism and Basic Income», en D. Leighton y S. White (eds.), Building a Citizen Society: The Emerging Politics of Republican Democracy, Londres: Lawrence \& Wishart.

Bollier, D. (2006): «Using Stakeholder Trusts to Reclaim Common Assets», en W. Paxton y S. White (eds.), The Citizen's Stake: Exploring the Future of Universal Asset Policies, Bristol: Policy Press. 
Carter, I. (2012): «Left-libertarianism and the Resource Dividend», en K. Widerquist y M.Howard (eds.), Alaska's Permanent Fund Dividend: Examining its Suitability as a Model, Basingstoke: Palgrave.

Carter, I., Kramer, M. y Steiner, H. (eds.) (2007): Freedom: A Philosophical Anthology, Oxford: Blackwell.

Casassas, D. (2007): "Basic Income and the Republican Ideal: Rethinking Material Independence in Contemporary Societies», Basic Income Studies, 2(2), pp. 1-7.

Casassas, D. (2010): La ciudad en Ilamas. La vigencia del republicanismo comercial de Adam Smith, Barcelona: Montesinos.

Cohen, G.A. (1995): Self-Ownership, Freedom, and Equality, Cambridge: Cambridge University Press.

Daniels, N. (1989): «Equal Liberty and Unequal Worth of Liberty», en N. Daniels (ed.), Reading Rawls, Stanford: Stanford University Press.

Domènech, A. y Raventós, D. (2007): «Property and Republican Freedom: An Institutional Approach to Basic Income», Basic Income Studies, 2(2), pp. 1-8.

Dowding, K., De Wispelaere, J. y White, S. (2003): "Stakeholding. A New Paradigm in Social Policy», en K. Dowding, J. De Wispelaere y S. White (eds.), The Ethics of Stakeholding, Basingstoke: Palgrave.

Esping-Andersen, G. (1990): The Three Worlds of Welfare Capitalism, Cambridge: Polity Press.

Fama, E.F. y M.C. Jensen (1983): «Separation of Ownership and Control»,
Journal of Law and Economics, 26, pp. 301-325.

Frank, R. y Cook, P.J. (1995): The Winner-Take-All Society. Why the Few at the Top Get So Much More Than the Rest of Us, New York: Free Press.

Freeman, S. (2001): "llliberal Libertarians: Why Libertarianism Is Not a Liberal View», Philosophy \& Public Affairs, 30(2), pp. 105-151.

Goldsmith, S. (2005): "The Alaska Permanent Fund: An Experiment in Wealth Distribution», en G. Standing (ed.), Promoting Income Security as a Right. Europe and North America, Londres: Anthem Press.

Goldsmith, S. (2012): «The Economic and Social Impacts of the Permanent Fund Dividend on Alaska», en K. Widerquist y M. Howard (eds.), Alaska's Permanent Fund Dividend: Examining its Suitability as a Model, Basingstoke: Palgrave.

Goodhart, M. (2007): «None So Poor that $\mathrm{He}$ is Compelled to Sell Himself: Democracy, Subsistence and Basic Income», en S. Hertel y L. Minkler (eds.), Economic Rights: Conceptual, Measurement and Policy Issues, Cambridge: Cambridge University Press.

Grey, T . (1980): «The Disintegration of Property», en J.R. Pennock y J.W. Chapman (eds.), NOMOS XXII: Property, Nueva York: New York University Press. Griffin, C. (2012): «Stakeholding Through the Permanent Fund Dividend: Fitting Practice to Theory», en K. Widerquist y M. Howard (eds.), Alaska's Permanent Fund Dividend: Examining its Suitability as a Model, Basingstoke: Palgrave. 
Haagh, L. (2011): «Basic Income, Social Democracy and Control over Time», Policy \& Politics, 39(1), pp. 43-66.

Harrington, J. (1992) [1656]: The Commonwealth of Oceana and A System of Politics, ed. a cargo de J.G.A. Pocock, Nueva York: Cambridge University Press. Howard, M. (2012): «A Cap on Carbon and a Basic Income: A Defensible Combination in the U.S.?», en K. Widerquist y M. Howard (eds.), Alaska's Permanent Fund Dividend: Examining its Suitability as a Model, Basingstoke: Palgrave.

Meade, J (1964): Efficiency, Equality and the Ownership of Property, Londres: Allen Unwin.

Murray, C. (2006): In Our Hands: A Plan to Replace the Welfare State, Washington D.C.: AEl Press.

Nozick, R. (1974): Anarchy, State, and Utopia, Oxford: Blackwell.

Otsuka, M. (2003): Libertarianism Without Inequality, Oxford: Oxford University Press.

Paine, T. (1997) [1797]: «Agrarian Justice», en B. Kuklick (ed.), Thomas Paine: Political Writings, Cambridge: Cambridge University Press.

Pettit, P. (1993): The Common Mind: An Essay on Psychology, Society and Politics, Nueva York: Oxford Univ. Press.

Pettit, P. (1997): Republicanism: A Theory of Freedom and Government, Nueva York: Oxford University Press.

Pettit, P. (1999): «Republican Freedom and Contestatory Democratization», en I. Shapiro y C.Hacker-Cordón (eds.), Democracy's Value, Cambridge: Cambridge University Press.

Pettit, P. (2000): «Democracy, Electoral and Contestatory», Nomos, 42, pp. 105-44.
Pettit, P. (2001): A Theory of Freedom: From the Psychology to the Politics of Agency, Oxford: Oxford University Press. Pettit, P. (2003): «Agency-freedom and Option-freedom», Journal of Theoretical Politics, 15(4), pp. 387-403.

Pettit, P. (2006): «Freedom in the Market», Politics, Philosophy and Economics, 5(2), pp. 131-149.

Pettit, P. (2008): «Three Conceptions of Democratic Control», Constellations, 15(1), pp. 46-55.

Pettit, P. (2009): «Varieties of Public Representation», en I. Shapiro et al. (eds.), Political Representation, Cambridge: Cambridge University Press.

Raventós, D. (2007): Basic Income: The Material Conditions of Freedom, Londres: Pluto Press.

Raventós, D. y Casassas, D. (2004): «La Renta Básica y el poder de negociación de 'los que viven con permiso de otros'», Revista Internacional de Sociología, 34.

Rawls, J. (1993): Political Liberalism, Nueva York: Columbia University Press. Rawls, J. (1999) [1971]: A Theory of Justice (edición revisada), Cambridge, MA: Harvard University Press.

Rousseau, J.J. (2010) [1754]: Discurso sobre el origen y los fundamentos de la desigualdad entre los hombres y otros escritos, Madrid: Tecnos.

Skinner, Q. (1992): «On Justice, the Common Good, and the Priority of Liberty», en C. Mouffe (ed.), Dimensions of Radical Democracy. Pluralism, Citizenship, Community, Londres/N. York: Verso. Skinner, Q. (1998): Liberty before Liberalism, Cambridge: Cambridge University Press. 
Sunstein, C. (1993): After the Rights Revolution: Reconceiving the Regulatory State, Cambridge, MA: Harvard University Press.

Vallentyne, P. (2003): "Self-Ownership and Equality: Brute Luck, Gifts, Universal Dominance and Leximin», en $A$. Reeve y A. Williams (eds.), Real Libertarianism Assessed, Basingstoke: Palgrave.

Vanderborght, Y. y Van Parijs, P. (2005) : L'allocation universelle, París: La Découverte.

Van Donselaar, G. (2008): The Right to Exploit, Nueva York: Oxford University Press.

Van Parijs, P. (1995): Real Freedom for All: What (if anything) Can Justify Capitalism?, Oxford: Oxford University Press.

Waldron, J. (1988): The Right to Private Property, Oxford: Clarendon Press.

Walzer, M. (1983): Spheres of Justice, Nueva York: Basic Books.

White, S. (2011): «Basic Income versus Basic Capital: Can We Resolve the Disagreement?», Policy and Politics, 39 (1), pp. 67-81.
Widerquist, K. (2012): "Citizens Capital Accounts", en K. Widerquist y $M$. Howard (eds.), Alaska's Permanent Fund Dividend: Examining its Suitability as a Model, Basingstoke: Palgrave.

Widerquist, K. y Howard, M. (eds.) (2012a): Alaska's Permanent Fund Dividend: Examining its Suitability as a Model, Basingstoke: Palgrave.

Widerquist, K. y Howard, M. (2012b): «Introduction: Success in Alaska», en K. Widerquist y M. Howard (eds.), Alaska's Permanent Fund Dividend: Examining its Suitability as a Model, Basingstoke: Palgrave.

Winter, S. (2012): «Climate Change, Complicity, and Compensation», en $\mathrm{K}$. Widerquist y M. Howard (eds.), Alaska's Permanent Fund Dividend: Examining its Suitability as a Model, Basingstoke: Palgrave.

Wolff, J. (1991): Robert Nozick: Property, Justice and the Minimal State, Cambridge: Polity Press.

Wright, E.O. (2006): «Basic Income as a Socialist Project», Basic Income Studies, 1(1), pp. 1-11. 


\section{Notas}

1 El pago más reciente, satisfecho en octubre de 2010, alcanzó los 1.281 dólares por persona. Sin embargo, la cuantía del subsidio puede fluctuar considerablemente como consecuencia de la evolución del valor de los ingresos del APF (<http://www. apfc.org $>$ ). Para un análisis pormenorizado de la historia, la estructura y el funcionamiento del APF y del PFD, véanse Goldsmith (2005, 2012).

2 Se ha llegado a afirmar que el PFD es la causa de que Alaska se haya convertido en el estado más igualitario de Estados Unidos (Vanderborght y Van Parijs, 2005: 25). En nuestra opinión, a pesar de la evidencia de ciertos efectos igualadores del PFD en los niveles de renta después de impuestos, el sostén empírico de dicha afirmación sigue siendo débil.

3 Para una visión general de posibles justificaciones alternativas del modelo de Alaska, véase Widerquist y Howard (2012b).

${ }^{4}$ Sobre la cláusula lockeana, véase especialmente Nozick (1974). Para debates posteriores al respecto, véanse Waldron (1988) y Wolff (1991).

5 Para un análisis crítico de este punto, véanse Arneson (2010) y Carter (2012). Como es sabido, Philippe Van Parijs, el más renombrado defensor de la renta básica, se refiere a su particular versión del libertarianismo de izquierdas como «libertarianismo real» (Van Parijs, 1995).

6 Véase Van Donselaar (2008) para una posible complicación de este argumento.

7 Para una caracterización alternativa del libertarianismo y para una defensa libertariana del reparto del valor de los recursos naturales que no se basa en la idea de la propiedad común de los mismos, véase Carter (2012).

8 Hemos utilizado aquí la traducción castellana de Antoni Domènech para Paidós (Barcelona, 1999, pp. 81-2).

9 El liberalismo, incluidas sus vertientes igualitarias, también se compromete con la noción de libertad como no-interferencia. En realidad, el hecho de que el libertarianismo deba ser visto o no como una subespecie del liberalismo es algo que ha generado cierta controversia. Philip Pettit (1997) ha sugerido que, en lo que respecta a su comparación con el republicanismo, liberalismo y libertarianismo pueden ser equiparados. En cambio, Samuel Freeman (2001) considera, como el propio Rawls (1993), que liberalismo y libertarianismo tienen poco en común. En este capítulo dejamos de lado la perspectiva liberal, para centrarnos exclusivamente en la republicana.

10 Los republicanos comparten con los libertarianos de izquierdas esta concepción «social» (o agency-based) de la libertad, pues ambos asocian la ausencia de libertad a actos perpetrados por los demás; pero así como los libertarianos se centran en la interferencia, los republicanos se muestran preocupados ante la dependencia.

11 Posteriormente, la idea de una democracia de propietarios fue adoptada por John Rawls (1999). Para un análisis del sentido normativo y de las implicaciones institucionales del proyecto de una democracia de propietarios, véase Birnbaum y Casassas (2008).

12 Para un análisis republicano de la «renta básica» propuesta por Thomas Paine, véase Raventós (2007).

13 Para un análisis de posibles justificaciones normativas de distintos esquemas de política fiscal realizadas de acuerdo con el principio de auto-propiedad, véase Vallentyne (2003).

14 Por supuesto, puede ocurrir que, en tanto que individuos, algunos libertarianos de izquierdas se muestren profundamente preocupados por la pobreza y decidan pasar a la acción para reducirla. Pero ello equivale a caridad, no al tipo de lucha sistemática contra la pobreza, como una cuestión de derecho, que los republicanos exigen. La teoría política libertariana, la de derechas y la de 
izquierdas, poco tiene que decir del hecho de que algunos vivan sus vidas en condiciones de pobreza extrema.

${ }^{15}$ Sin ir más lejos, de ahí el sugerente subtítulo de la monografía de Philip Pettit (1997) sobre el republicanismo: «Una teoría sobre la libertad y el gobierno».

${ }^{16}$ Como es bien sabido, la importancia de establecer una base o suelo económico atraviesa el conjunto del debate sobre la renta básica.

17 Curiosamente, cuando se afirma que el PFD ha hecho de Alaska el estado más igualitario de Estados Unidos, no se presta atención alguna a la cuestión de la (des)igualdad de género en el acceso a la renta o a las oportunidades de empleo.

18 Sobre patrones de gasto del PFD, véase el análisis de la evidencia disponible que se ofrece en Goldsmith (2005).

19 Pese a que Goldsmith (2012) está en lo cierto cuando señala que existe un buen número de mecanismos a través de los cuales la certeza de un flujo regular de renta puede tener importantes efectos positivos en ciertos grupos sociales -especialmente en las comunidades rurales del estado-, nuestra preocupación con respecto a la cuantía satisfecha se mantiene intacta: la magnitud de la base económica que confiere el PFD es demasiado reducida para que tenga un impacto significativo en términos de libertad republicana.

20 Ello nos permite afirmar que los defensores republicanos de la renta básica manejan unos requisitos más restrictivos que los propuestos por Philippe Van Parijs en su análisis del nivel deseable de la renta básica. Se- gún Van Parijs (1995), la renta básica debería situarse en su nivel más alto sostenible. Según los republicanos, en cambio, en caso de que el "nivel más alto sostenible» sea demasiado bajo, puede tener sentido plantear la posibilidad de no emplear el capital político necesario para introducir una renta básica de dicho nivel, en especial cuando se sabe que existen otras medidas que pueden promover la libertad republicana en mayor medida que esa renta básica de escasa cuantía.

21 Para una defensa de la segunda opción, véase especialmente Murray (2006).

22 Para un análisis crítico, véanse Arneson (1995) y Barry (1995, 2005).

${ }^{23}$ Nótese que el «control virtual» es perfectamente aceptable desde una óptica republicana (Pettit, 2008, 2009).

${ }^{24}$ Goldsmith (2005: 558) explica que en algún momento se consideró la posibilidad de liquidar el APF «distribuyendo entre todos los residentes la recaudación de modo equitativo a través de un único pago de 40.000 dólares». Dicha propuesta fue desestimada. Para un análisis de las ventajas e inconvenientes de concebir el PFD como una renta básica o como un capital básico, véase Griffin (2012). Para un análisis general de la propuesta del capital básico, véanse Ackerman y Alstott (1999), Dowding, De Wispelaere y White (2003) y White (2011).

${ }^{25}$ Winter (2012) ofrece una crítica radical del uso de impuestos sobre recursos naturales por los efectos nocivos que ello puede tener sobre el medioambiente. Howard (2012), en cambio, aboga por la opción contraria, esto es, por defender tales figuras impositivas. 